\title{
Environment and economic growth: is the rule of law the go-between? The case of high-income countries
}

\author{
Concetta Castiglione 1 , Davide Infante ${ }^{2^{*}}$ and Janna Smirnova ${ }^{2}$
}

\begin{abstract}
Background: The links between pollution, institutions, and economic growth may be not so univocal as argued in the literature, as these factors may influence each other since some reverse causality may exist between them. The understanding of this relationship is important for identifying appropriate policies for sustainable development.

Methods: We investigate the long-run relationship between pollution, institutions, and economic growth, considering as variables carbon dioxide emissions, rule of law, and income. The model offers an analysis of causality direction using a panel-VAR approach for the period 1996-2010 for 33 high-income countries that include advanced, emerging, and former-transition economies.

Results: The results demonstrate a positive reverse causality relationship between the rule of law and income, indicating that higher income implies stronger rule of law and vice versa. The rule of law is found to have a negative relationship with pollution, confirming that the enforcement of rules is "a conditio sine qua non" to control emissions. No causality relationship is found for pollution and income that can be due to the different stages of economic development of emerging, former-transition, and developed economies, implying heterogeneity in their environmental protection policies.

Conclusions: We argue that the rule of law matters both for economic growth and environment, working as a go-between and creating a win-win situation, where stronger institutions increase the levels of income and vice versa. In order to enhance sustainable development, a policy maker should allocate additional resources for both monitoring the application of the rule of law and its enforcement.
\end{abstract}

Keywords: Environment; Rule of law; Growth; High-income countries

\section{Background}

\section{Introduction}

The goals of sustainable development cannot be achieved without incurring in two important factors. One is the state intervention and, therefore, the quality of governance. In fact, environmental protection measures are rarely adopted without regulatory stimuli. The other factor, tightly linked to the first one, is the quality of institutional context. Institutions determine the implementation and outcome of governmental policies, reflecting the capacity to manage environmental issues. The quality

\footnotetext{
* Correspondence: davide.infante@unical.it

${ }^{2}$ Department of Economics, Statistics and Finance, University of Calabria,

87036, Campus di Arcavacata di Rende, Cosenza, Italy

Full list of author information is available at the end of the article
}

of institutions influences the degree by which a society is involved in the process of environmental renaissance. Stronger institutions imply environmental awareness, thus opting for environmental protection as an active sustainability policy. The above mechanism is, as argued, strongly tied with economic growth since stronger institutional context enhances the process of economic development.

It is often maintained that an increase in income coming from the reinforcement of institutions implies an increase in demand for environmental protection, leading to pollution abatement. Therefore, the reinforcement of the institutional context can create a win-win situation in the sense that it may improve both environmental protection and the level of income of a country. Alternatively, if the reinforcement of the institutional context does not imply

\section{实 Springer}

(c) 2015 Castiglione et al. Open Access This article is distributed under the terms of the Creative Commons Attribution 4.0 International License (http://creativecommons.org/licenses/by/4.0/), which permits unrestricted use, distribution, and reproduction in any medium, provided you give appropriate credit to the original author(s) and the source, provide a link to the Creative Commons license, and indicate if changes were made. 
an increase in income, environmental protection is more difficult to implement. A similar mechanism can be addressed to the role of income that enhances institutional enforcement and, therefore, pollution abatement. In turn, as argued, pollution should be given only a partial role in the reverse causality direction. However, the increase of pollution could imply greater income if we consider emerging and developing countries that do possess strong institutional context, but it should not be so in developed economies where strong institutions contribute to abate pollution.

An example of these scenarios is the development of shale mining that has started in recent years in different countries. Given its potentially negative impact on environment, shale mining can represent an opportunity for environmentally friendly economic growth in the countries that have stringent institutions [1]. At the same time, economic growth that is accompanied by severe environmental damage is the threat that countries with a still weak institutional context may face [2].

Although there exists a wide range of literature focusing on the relationship between economic growth, environmental quality, and institutional context, little attention has been paid to their causal relationship. Most of these studies have considered a unidirectional causal relationship, treating income, emissions, or institutions as exogenous variables [3-5]. While, we argue that reverse causality may exist. This study improves upon previous studies by providing the evidence of the existence of a long-term relationship between rule of law, carbon dioxide emissions, and income per capita and by investigating the endogeneity of the three variables in a panel data of high-income countries for the period from 1996 to 2010. For the best of our knowledge, no empirical evidence has yet emerged regarding this issue.

\section{Related literature}

As known from the literature, stronger institutional context enhances the process of economic development and growth [6-8]. At the same time, economic growth has itself an important impact on environmental quality. $\mathrm{Nu}-$ merous authors demonstrate that the level of pollution increases gradually starting from lower levels of per capita income but then decreases, after reaching a peak at higher levels of income $[9,10]$.

As for the links between environment and institutions, numerous scholars have demonstrated that the successful implementation of environmental policies is determined by institutional strength. For example, corruption has been shown to have a negative effect on environmental quality, undermining the effectiveness of environmental policies $[3,11,12]$. In contrast, strong institutions in the form of political liberties, civil rights, and democracy positively contribute to environmental quality [13], as have secure property rights [4] and legal protection [14]. Reinforcement of the rule of law is found to reduce the degree of environmental damage and to enhance the application of sustainable policies $[15,16]$. Finally, economic openness [17] and flexible state policies [18] are proved to incentivise the adoption of environmental technologies. Other studies analyze the diffusion of new environmental technologies and the level of pollution in relation to persisting rent-seeking activities and the corruption of economic agents [19-21].

Finally, from a methodological point of view, our work is related to [22] where the link between economic openness, pollution, and income is analyzed by applying the Vector Autoregression methodology (VAR) to crosssection data of heterogeneous countries. Despite some differences in the specification of the empirical model and estimation methodologies, the distinguishing feature of our paper is the analysis of the interdependence between pollution, institutional context, and economic growth for high-income economies. In particular, we focus our attention to the analysis of causality direction between three important factors regarding sustainable development: carbon dioxide emissions, rule of law, and income per capita, using a panel-VAR approach.

\section{Methods}

High-income countries: income, rule of law, and carbon dioxide emissions

Although the causality relationship between environmental quality, institutions, and income is expected to be heterogeneous among countries, an important emphasis in understanding this relationship should be given to high-income economies. The rationality behind this is that high-income economies constitute a model for making comparisons for other countries since these countries normally define the rules of the game in a sustainability perspective. This is done not only by setting environmental regulations but also by their enforcement assured by their more stringent institutional context. It should be noted that, although these economies are part of the same income group, their points of departure are very different, given that their similar levels of income are obtained by different environmental tendencies. In fact, among these countries, there are mature economies, characterized by intensive domestic consumption and transferring production processes abroad together with the emission of pollutants. There are also emerging economies that rely upon resources exportation or importation of production processes at home markets which damage their environment. Some former-transition countries are part of the highincome group. These countries have not yet started to transfer their production processes abroad and have therefore a larger domestic production. 
As for an institutional indicator, we take into consideration the rule of law given its importance for the implementation of environmental policy as well as for social awareness of environmental sustainability. Although some studies take into account the rule of law [23-25], to the best of our knowledge, there are very few works $[26,27,15]$ that analyze this institution from an environmental perspective. As for the choice of the pollutant, we concentrate our attention to carbon dioxide, which is one of the most considered energy-related pollutant and a major source of the greenhouse effect. As known, one of the primary sustainability challenges consists in the transition of energy to sustainable energy supply systems aimed at the reduction of carbon dioxide emissions. The reduction of this type of pollution is always socially mediated through environmental policies, primarily through energy policies, and rarely occurs by natural forces. Clearly, the observable trends of carbon dioxide emissions are expected to reflect the degree of environmental awareness of the society as well as the functionality of sustainability-oriented policies.

The relationship between economic development, environmental quality, and institutional enforcement can be described as follows. The rule of law enforcement leads to an increase in income that brings about higher pollution in early stages of economic development. However, the increase in income induced by institutional development causes economic agents to increase the demand for a clean environment. Consequently, a country tends to follow a pattern of rising pollution levels as institutional development proceeds, which will be accompanied by declining pollution and better institutional quality at a more advanced stage of economic development.

These linkages are illustrated in Fig. 1 for 33 high-income economies, classified by the World Bank, that include 18 developed, 8 emerging, as well as 7 post-transition economies. The figure shows the distribution of income, carbon dioxide, and rule of law among the countries. The height of bars corresponds to the percentage of a country's values of each variable (income, rule of law, and emissions) with respect to the country with the highest value of these variables, considering the mean value of the period. As can be seen, despite some exceptions, countries with higher levels of pollution are also those that have lower levels of rule of law. Moreover, although there are no highly accentuated differences in income, since the countries belong to the same income group, it can be noted that countries that produce higher pollution rates have also lower income levels. In fact, among the first ten countries with the higher carbon dioxide emissions, eight belong to emerging or post-transition economies.

\section{Model and data}

The relationship between the three variables is estimated by applying the vector autoregression model for panel data, a technique that "combines the traditional VAR approach, which treats all the variables in the system as endogenous, with the panel-data approach, which allows for unobserved individual heterogeneity" [28]. The model specified as a first-order VAR, in the reduced form, can be expressed in the following way:

$$
y_{i t}=A_{0}+A_{1} y_{i t-1}+f_{i}+d_{t}+u_{i t}
$$

where $y_{i t}$ is a $(3 \times 1)$ vector of our variables (rule of law, pollution, and income), $f_{i}$ is a vector of country-specific effects, $d_{t}$ is a vector of time effect, and $u_{i t}$ is an independent and identically distributed (i.i.d.) disturbance vector.

The vector of country-specific effects is a necessary part of the model, given that in applying a panel-VAR, the restriction that the underlying structure is the same for each cross-sectional unit is required [28]. In order to allow for individual heterogeneity in the levels, fixed effects are introduced and denoted by $f_{i}$ in the model. Following [28] and [29], the variables are time-demeaned and the fixed individual effects are removed by the Helmert transformation method. This procedure removes the mean of all the future observations available for each country-year. This transformation preserves the orthogonality between transformed variables and lagged regressors so that according to the abovementioned authors [28] and [29], lagged regressors can be used as instruments to estimate the coefficients by GMM. Finally, countryspecific time dummies $\left(d_{t}\right)$ are added to the model to capture aggregate, country-specific macro shocks that may affect countries in the same way. These dummies are eliminated by subtracting the means of each variable calculated for each country-year (see [28] for more details).

As noted above, the panel data contains 33 highincome countries, classified by the World Bank for the period from 1996 to 2010. The sample contains countries that are unified by income criteria as they are classified by the World Bank as high-income countries. That is a good starting point, since our aim is to verify a longrun relationship using countries that were not "cherry picked" to fit ex-ante criteria. For example, they do not all belong to the same "club," such as the OECD, where the accession procedure is complex as it involves a series of examinations to assess a country's ability to meet OECD standards in a wide range of policy areas. For us, it is most important to see if countries that had different patterns of development register the same relationship between income, pollution, and the rule of law.

The income variable (GDP), expressed as GDP per capita (in constant 2005 US\$) as well as the pollution variable (Poll), expressed as carbon dioxide emissions per capita (in $\mathrm{kg}$ per 2011 PPP \$ of GDP), are taken from [30]. The index of rule of law (RoL) that varies from -2.5 to +2.5 is 


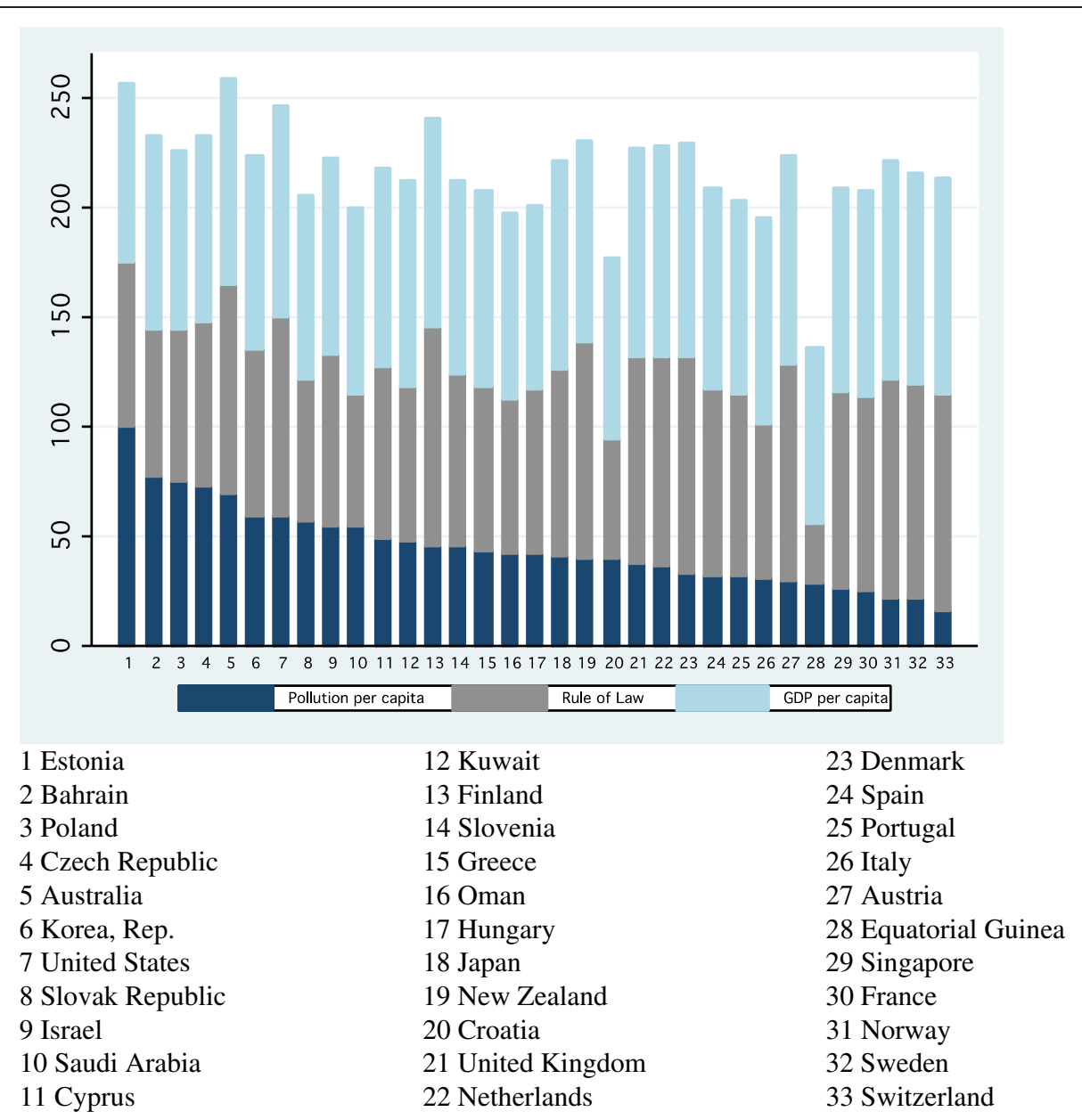

Fig. 1 Distribution of GDP, pollution, and rule of law among countries

provided by [31]. Table 1 displays a summary statistics of our variables.

\section{Results and discussion}

The first step of our analysis is to provide the unit root test of our variables. There is a variety of methods proposed for implementing the stationarity tests for panel data, and each has been widely used in the literature of applied economics. In this study, five stationarity tests are used: LLC [32], IPS [33], Breitung [34], Fisher [35], and the Hadri [36]. The results are shown in Table 2. The five tests have different null hypotheses. In particular, the first four tests have the null hypothesis of nonstationarity ( $(1)$ behavior), while the Hadri test has a

Table 1 Descriptive statistics

\begin{tabular}{llllll}
\hline Variable & Obs & Mean & Std. Dev. & Min & Max \\
\hline GDP & 495 & $26,249.66$ & $14,128.08$ & 1093.21 & $67,804.55$ \\
Poll & 495 & 0.31 & 0.14 & 0.04 & 1.13 \\
RoL & 495 & 1.07 & 0.72 & -1.45 & 2.00 \\
\hline
\end{tabular}

null of stationarity (I(0) behavior). With the exception of the LLC test, which confirms that RoL and Poll are stationary variables, all the other tests display that the variables appear to be non-stationary in level but stationary in the first differences, taking into account the logarithms for GDP and Poll.

We, therefore, provide cointegration tests (Table 3) based on error correction, developed by [37] for panel data. The null hypothesis of these tests is the absence of cointegration. The $G a$ and $G t$ statistics test if cointegration exists for at least one observation. The $P a$ and $P t$ statistics pool information over all the cross-sectional units to test whether there exists cointegration for the panel as a whole. According to our results, cointegration can be accepted only at $10 \%$ and not in all cases. Since the level of significance is very low, we can proceed to estimate the vector auto-regressive model.

The estimation results of panel-VAR for high-income countries, shown in Table 4, demonstrate the long-run relationship between income, pollution, and the rule of law. The results show that in these countries, income 
Table 2 Unit root test

\begin{tabular}{llllll}
\hline & LLC & IPS & Breitung & Fisher & Hadri \\
\hline GDP & -0.554 & 0.003 & 1.078 & 68.221 & 24.663 \\
& 0.289 & 0.501 & 0.859 & 0.402 & 0.000 \\
d.GDP & -4.909 & -3.676 & -4.669 & 142.41 & 1.227 \\
& 0.000 & 0.000 & 0.000 & 0.000 & 0.110 \\
Poll & -3.746 & 2.907 & 3.154 & 42.061 & 16.464 \\
& 0.000 & 0.998 & 0.999 & 0.991 & 0.000 \\
d.Poll &.. & -7.022 & -3.997 & 267.87 & -1.444 \\
& & 0.000 & 0.000 & 0.000 & 0.926 \\
RoL & -3.914 & -1.354 & -1.684 & 84.69 & 14.11 \\
& 0.000 & 0.088 & 0.046 & 0.061 & 0.000 \\
d.RoL &.. & -9.076 & -7.409 & 294.89 & -0.067 \\
& & 0.000 & 0.000 & 0.000 & 0.527 \\
\hline
\end{tabular}

Note: $p$ value in italics

and the rule of law variables reinforce each other. Higher income implies better institutional quality (Eq. 2 in Table 4), while a stronger rule of law leads to a higher degree of GDP per capita (Eq. 1 in Table 4) and a lower level of pollution (Eq. 3 in Table 4). This means that wealthier countries are in a virtuous cycle since by reinforcing their rule of law they produce higher income that in turn calls for a stronger institutional context.

Interestingly, the results demonstrate that the institutional context plays an important role in increasing environmental protection: a high rule of law implies lower emission levels (Eq. 3 in Table 4), while, as expected, pollution has no influence on the rule of law (Eq. 2 in Table 4). The relationship between income and pollution (Eqs. 1 and 3 in Table 4) is not significant. We would expect that either intensive economic activity should produce more pollution due to production and consumption or, on the contrary, intensive economic activity should produce less pollution due to environmental awareness. The fact that income may not influence pollution and vice versa could be given to the different stages of economic development of emerging, former-transition, and developed economies, and, consequently, for their heterogeneous degree of environmental protection.

The final step of this analysis is to evaluate impulse responses that refer to the effect of a shock in a variable on the other variables in the model. As it can be seen

Table 3 Panel cointegration test

\begin{tabular}{lll}
\hline Statistic & Value & Robust $p$ value \\
\hline $\mathrm{Gt}$ & -0.940 & 0.886 \\
$\mathrm{Ga}$ & -2.998 & 0.427 \\
$\mathrm{Pt}$ & -9.033 & 0.088 \\
$\mathrm{~Pa}$ & -4.512 & 0.016 \\
\hline
\end{tabular}

Robust critical value obtained bootstrapping with 1000 replications
Table 4 P-VAR estimation results

\begin{tabular}{lccc}
\hline & Parameter & S. E. & Student's $t$ \\
\hline Eq. 1: dep. Var: GDP(t) & & \\
GDP(t-l) & $0.808^{* * *}$ & 0.071 & 11.390 \\
Poll(t-l) & -0.024 & 0.031 & -0.783 \\
RoL(t-l) & $0.054^{*}$ & 0.033 & 1.651 \\
Eq. 2: dep. Var: RoL(t) & & \\
GDP(t-l) & $0.053^{* * *}$ & 0.018 & 2.950 \\
Poll(t-l) & -0.020 & 0.018 & -1.131 \\
RoL(t-l) & $0.743^{* * *}$ & 0.032 & 22.984 \\
Eq. 3: dep. Var: Poll(t) & & \\
GDP(t-l) & 0.002 & 0.112 & 0.017 \\
Poll(t-l) & $0.810^{* * *}$ & 0.107 & 7.568 \\
RoL(t-l) & $-0.103^{* *}$ & 0.049 & -2.106 \\
\hline
\end{tabular}

The three variable VAR model is estimated by GMM; country-time and fixed effects are removed prior to estimation. Reported numbers show the coefficients of regressing the row variables on lags of the column variables. Heteroskedasticity adjusted $t$-statistics are reported

***Indicates significance at $1 \%$ level; **indicates significance at $5 \%$ level;

*indicates significance at $10 \%$ level

from Table 5, the shocks have either a positive or negative impact on the rule of law, pollution, and income. The impulse responses are consistent with the results obtained by VAR analysis and confirm our previous findings. It should however be noted that the estimated impulse responses are characterized by the shocks that appear to have persistent effects. As Table 5 demonstrates, the impulse responses are significantly different from zero, which suggests that shocks may have persistent influence in our framework.

\section{Conclusions}

Our paper contributes to the understanding of the relationship between environmental quality, institutional context, and economic growth. As known, some links of the above relationship have already been emphasized in the literature. In fact, there is a large consensus on the positive contribution of institutions to economic development and environmental quality. A smaller consensus is expressed on the impact of economic development on the environment that is found to be positive or negative, depending on the stage of the economic development itself. At the same time, to the best of our knowledge, there is very little contribution on the causality relationships between the above three variables that, as we argue, play a crucial role for economic policies that search to reconcile growth and a clean environment. Our work aims, therefore, to fill in these lacunae and investigates on a long-run causal relationship between carbon emissions, rule of law, and income.

We claim that this relationship has a particular importance for high-income economies that, as global country leaders, plays a decisive role in determining 
Table $\mathbf{5}$ Impulse responses of variable in varname to the shock in column variable

\begin{tabular}{llllll}
\hline Varname & $s$ & Order & GDP & Poll & RoL \\
\hline GDP & 0 & 1 & 0.0384 & 0.0000 & 0.0000 \\
& 1 & 1 & 0.0312 & -0.0027 & 0.0032 \\
& 2 & 1 & 0.0254 & -0.0045 & 0.0051 \\
& 3 & 1 & 0.0208 & -0.0057 & 0.0061 \\
& 4 & 1 & 0.0171 & -0.0063 & 0.0066 \\
& 5 & 1 & 0.0141 & -0.0065 & 0.0066 \\
Poll & 6 & 1 & 0.0117 & -0.0065 & 0.0064 \\
& 0 & 2 & 0.0014 & 0.1089 & 0 \\
& 1 & 2 & 0.0009 & 0.0883 & -0.0061 \\
& 2 & 2 & 0.0003 & 0.0719 & -0.0095 \\
& 3 & 2 & -0.0002 & 0.0587 & -0.0111 \\
& 4 & 2 & -0.0007 & 0.048 & -0.0115 \\
& 5 & 2 & -0.001 & 0.0394 & -0.0113 \\
& 6 & 2 & -0.0013 & 0.0324 & -0.0106 \\
& 0 & 3 & 0.0035 & -0.002 & 0.0594 \\
& 1 & 3 & 0.0046 & -0.0037 & 0.0442 \\
& 2 & 3 & 0.005 & -0.0047 & 0.0331 \\
& 3 & 3 & 0.0051 & -0.0052 & 0.025 \\
& 4 & 3 & 0.0049 & -0.0053 & 0.0192 \\
& 5 & 3 & 0.0045 & -0.0053 & 0.0148 \\
& 6 & 3 & 0.0041 & -0.0051 & 0.0116 \\
\hline & & & & &
\end{tabular}

global environmental quality through both their economic and sustainability policies. For this reason, we implemented in our analysis a set of panel data that considers 33 high-income countries of World Bank classification (that includes developed as well as former-transition and emerging economies) for a period of 13 years (1996-2010).

Our results confirmed the presence of a complex relationship between carbon dioxide emissions, rule of law index, and income per capita in a set of panel data. They demonstrated a positive double causality long-run relationship between the rule of law and income per capita, indicating that as income increases, more respect for the rule of law is acquired and vice versa. We also found that the rule of law has a negative relationship with pollution, confirming that the enforcement of rules is "a conditio sine qua non" to control pollution, while the reverse causality, i.e., that pollution influences the rule of law, does not hold. Moreover, the results demonstrated that pollution and income have no double causality relationship. This can be explained by the different stages of economic development of emerging, former-transition, and developed economies, which implies heterogeneity in environmental protection. We can conclude that, in high-income economies, a reinforcement of the rule of law leads to a win-win situation, where stronger institutions increase the levels of income and vice versa, with pollution reduction generated by institutional stringency and high income.

As an overall result, we can affirm that the rule of law is an institution that works in-between economic growth and environment. From these findings, some important policy implications can be drawn. Firstly, policy makers that aim to enhance economic growth can use this institution and be aware that it would promote not only growth but, in turn, would also reinforce the institutional context. Secondly, the reinforcement of the rule of law is essential for controlling the environmental quality. Independently of the policies adopted (taxes, subsidies, emission standards, etc.), to achieve the goals of sustainable development, it is crucial that the rules are clear, applied, and enforced. In turn, increasing pollution does not necessarily call for environmental awareness that, for some of the countries, could mean the weakness of environmental regulations and unenforced rule of law. Finally, it could be difficult for policy makers to address directly the relationship between economic growth and pollution and vice versa. The countries' patterns to reach a high level of income are very different and it is not easy to disentangle a significant relationship between growth and pollution that can characterize all the countries. This could explain the reasons why some countries are so reluctant to adhere to international protocols to reduce their pollution levels.

\section{Competing interests}

The authors declare that they have no competing interests.

\section{Authors' contributions}

The article was jointly prepared by all authors. All authors read and approved the final manuscript.

\section{Authors' information}

Concetta Castiglione is a Postdoc research fellow in the Department of Statistical Sciences at the University of Bologna. She holds a PhD in Economics from the Trinity College Dublin, Ireland, and a doctoral degree in Applied Economics from the University of Calabria, Italy. Her research interests are in the area of productivity and efficiency analysis, ICT investments, cultural participation, consumer demand, and environment policies. Her list of publications includes papers in referred academic journals and in edited books.

Davide Infante is an Associate Professor of Political Economy at the University of Calabria, where he teaches Microeconomics and Economics of Innovation. His research includes wide-ranging topics in theoretical and applied economics such as transition economies, economics of innovation, consumer demand, environmental protection among others, published in authored and co-authored books, and international academic journals.

Janna Smirnova is a Researcher in Economic Policy at the University of Calabria, where she teaches Economic Growth Theory and International Economics. She received her PhD at the University of Calabria after having obtained a Master's Degree in Economics from the University College Dublin. She has authored and co-authored many works on institutional development, environmental economics, economic growth, and organization that have been published in books and international referred journals. 


\section{Acknowledgements}

The authors wish to thank the Editors and two anonymous referees of this journal for their useful suggestions.

\section{Author details}

${ }^{1}$ Department of Statistical Sciences, University of Bologna, Bologna, Italy. ${ }^{2}$ Department of Economics, Statistics and Finance, University of Calabria, 87036, Campus di Arcavacata di Rende, Cosenza, Italy.

\section{Received: 21 August 2014 Accepted: 6 August 2015}

Published online: 25 August 2015

\section{References}

1. Centner TJ (2013) Oversight of shale gas production in the United States and the disclosure of toxic substances. Resour Policy 38:233-240

2. Krupnick A, Wang Z, Wang Y (2014) Environmental risks of shale gas development in China. Energ Policy 75:117-125

3. Cole MA (2007) Corruption, income and the environment: an empirical analysis. Ecol Econ 62(4):637-647

4. Culas RJ (2007) Deforestation and the environmental Kuznets curve: an institutional perspective. Ecol Econ 61(2-3):429-437

5. Dutt K (2009) Governance, institutions and the environmental-income relationship: a cross-country study. Econ Lett 1(4):705-723

6. Acemoglu D, Johnson S, Robinson JA (2001) The colonial origins of comparative development: an empirical investigation. Am Econ Rev 91(5):1369-01

7. Giménez G, Sanaú J (2007) Interrelationship among institutional infrastructure, technological innovation and growth. An empirical evidence. Appl Econ 39(10):1267-1282

8. Welsch H (2008) The welfare costs of corruption. Appl Econ 40(14):1839-1849

9. Dasgupta S, Mody A, Roy S, Wheeler D (2001) Environmental regulation and development: a cross-country empirical analysis. Oxford Econ Stud 29(2):173-187

10. Dinda S (2004) Environmental Kuznets curve hypothesis: a survey. Ecol Econ 49(4):431-455

11. Damania R, Fredriksson PG, Mani M (2004) The persistence of corruption and regulatory compliance failures: theory and evidence. Public Choice 121(3):363-390

12. Leitão A (2010) Corruption and the environmental Kuznets curve: empirical evidence for sulphur. Ecol Econ 69(11):2191-2201

13. Frankel JA, Rose AK (2002) Is trade good or bad for the environment? Sorting out the causality. NBER Working Paper 9201. NBER, Cambridge, MA

14. Di Vita G (2009) Legal families and environmental protection: is there a causal relationship? J Policy Model 31(5):694-707

15. Sanders MPT, Heldewerg MA, Straatman EJP, Wempe JFDB (2014). Energy policy by beauty contests: the legitimacy of interactive sustainability policies at regional levels of the regulatory state. Energy Sust Soc 4(4):1-13

16. Bhattarai M, Hammig M (2004) Governance, economics policy, and the environmental Kuznets curve for natural tropical forests. Environ Dev Econ 9(3):367-382

17. Lovely M, Popp D (2008) Trade, technology and the environment: why have poor countries regulated sooner? NBER Working Paper14286. NBER, Cambridge, MA

18. Kerr S, Newell RG (2003) Policy-induced technology adoption: evidence from the U.S. lead phasedown. J Dev Econ 51(3):317-343

19. Acemoglu D, Verdier T (2000) The choice between market failures and corruption. Am Econ Rev 9(1):194-211

20. Infante D, Smirnova J (2009) Rent-seeking under weak institutional environment. Econ Lett 104(3):118-121

21. Mookherjee D, Png IPL (1995) Corruptible law enforcers: how should they be compensated. Econ J 105(428):145-159

22. Baek J, Cho Y, Koo WW (2009) The environmental consequence of globalisation: a country-specific time-series analysis. Ecol Econ 68(8-9):2255-2264

23. Berggren N, Bjornskov C (2013) Does religiosity promote property rights and the rule of law? J Inst Econ 9(2):161-185

24. Butkiewicz JL, Yanikkaya $H$ (2006) Institutional quality and economic growth: maintenance of the rule of law or democratic institutions, or both? Econ Model 23(4):648-661
25. Dollar D, Kraay A (2000) Property rights, political rights, and the development of poor countries in the post-colonial period. World Bank Working Papers. Washington, DC., Available via http://citeseerx.ist.psu.edu/ viewdoc/summary?doi=10.1.1.196.264. Accessed July 2012

26. Castiglione C, Infante D, Smirnova J (2012) Rule of law and the environmental Kuznets curve: evidence for carbon emissions. Int J Sust Econ 4(3):254-269

27. Castiglione C, Infante D, Smirnova J (2014) Is there any evidence on the existence of an environmental taxation Kuznets curve? The case of European countries under their rule of law enforcement. Sustainability 6(10):7242-7262

28. Love I, Zicchino L (2006) Financial development and dynamic investment behaviour: evidence from panel VAR. Q Rev Econ Financ 46(2):190-210

29. Noy I, Nualsri A (2011) Fiscal storms: public spending and revenues in the aftermath of natural disasters. Environ Dev Econ 16(1):113-128

30. World Bank (2011) World development indicators., http://data.worldbank.org/ datacatalog/world-development-indicators. Accessed July 2012

31. Kaufmann D, Kraay A, Mastruzzi M (2010) The worldwide governance indicators: a summary of methodology, data and analytical issues. World Bank Policy Research Working Paper 5430

32. Levin A, Lin CF, Chu CSJ (2002) Unit root tests in panel data: asymptotic and finite sample properties. J Econometrics 108(1):1-24

33. Im KS, Pesaran MH, Shin Y (2003) Testing for unit roots in heterogeneous panel. J Econometrics 115(1):53-74

34. Breitung J (2000) The local power of some unit root tests for panel data. In: Baltagi BH (ed) Advances in Econometrics, vol 15, Nonstationary Panels, Panel Cointegration, and Dynamic Panels. JAI Press, Amsterdam, pp 161-178

35. Choi I (2001) Unit root tests for panel data. J Int Money Financ 20(2):249-272

36. Hadri K (2000) Testing for stationarity in heterogeneous panel data. Econ J 3(2):148-161

37. Westerlund J (2007) Testing for error correction in panel data. Oxford B Econ Stat 69(6):709-784

\section{Submit your manuscript to a SpringerOpen ${ }^{\circ}$ journal and benefit from:}

- Convenient online submission

- Rigorous peer review

- Immediate publication on acceptance

- Open access: articles freely available online

- High visibility within the field

- Retaining the copyright to your article

Submit your next manuscript at $>$ springeropen.com 